\title{
Stress relaxation behavior and creep rupture property of GH4145 alloy
}

\author{
Yanping Zeng ${ }^{1, a, *}$, Dazhi Yao ${ }^{1, b}$, Haojie Du ${ }^{1, c}$, Wenhe Cai ${ }^{2, ~ d}$, Zhichun Wang ${ }^{2}$ \\ e, Shuqing Dong ${ }^{2, \mathrm{f}}$, Weili $\mathrm{Li}^{2, \mathrm{~g}}$, Weidong Zhao ${ }^{2, \mathrm{~h}}$ \\ ${ }^{1}$ School of Materials Science and Engineering; University of Science and Technology Beijing, \\ Beijing, 100083, China \\ ${ }^{2}$ North China Electric Power Research Institute Co Ltd, Beijing, 100045, China \\ aemail: \\ zengyanping@mater.ustb.edu.cn, bemail: yaodazhi.ok@163.com, cemail: 623961551@qq.com, de \\ mail: caiwenhe@126.com, eemail: dachunw@126.com, 'email: \\ tree2061@163.com, ${ }^{9}$ email: liweili-1982@sohu.com, hemail: zhwd1103@163.com
}

Keywords: GH4145 alloy, stress relaxation behavior, creep rupture property

\begin{abstract}
The stress relaxation behavior and creep rupture property of GH4145 alloy were studied. The results show that GH4145 alloy has good resistance to stress relaxation. During the stress relaxation test at $566{ }^{\circ} \mathrm{C}$, the coarsening rate of secondary $\gamma^{\prime}$ particles was very slow and the hardness of the alloy increased due to the increase in the volume fraction of the dispersed secondary $\gamma^{\prime}$ particles and the precipitation of tertiary $\gamma^{\prime}$ particles. The relational expression between stress and creep rupture life for $\mathrm{GH} 4145$ alloy at $566^{\circ} \mathrm{C}$ was obtained. The creep rupture strength for times longer than that of the experimental data can be estimated by using this equation.
\end{abstract}

\section{Introduction}

GH4145 alloy is a precipitation-strengthened nickel-based superalloy, similar to Inconel X-750. It exhibits high strength and low creep rates up to a temperature of $900{ }^{\circ} \mathrm{C}$, together with good corrosion and oxidation resistance in a large number of media and oxidants [1] and is currently applied for bolts in middle/high-pressure cylinders of large capacity steam turbine [2] [3]. The bolts are usually subjected to tensile stress resulting from tightening during service. However, at high temperature environment, relaxation of such stress would take place. When the residual stress is less than the minimum sealing stress, the steam would escape from the joint face of the cylinder, causing an accident. Therefore, the stress relaxation behavior as well as the creep rupture property is also of critical importance for GH4145 alloy to ensure the safe operation of the supercritical (SC) and ultra-supercritical (USC) units. But little data on these subjects have been reported to date. The present study will focus on the stress relaxation behavior and creep rupture property of the alloy under supercritical conditions.

\section{Material and experimental procedures}

GH4145 alloy are used as the material for this study and its chemical composition is listed in Table 1 . The alloy was solution treated at $1130{ }^{\circ} \mathrm{C}$ for $2 \mathrm{~h}$ followed by cooling in air and then aged at $845{ }^{\circ} \mathrm{C} / 24 \mathrm{~h} / \mathrm{FC}+705{ }^{\circ} \mathrm{C} / 20 \mathrm{~h} / \mathrm{AC}$. The standard specimens, $10 \mathrm{~mm}$ in diameter and $50 \mathrm{~mm}$ in gauge-length, were prepared from the aged alloy. Stress relaxation tests were conducted at $566{ }^{\circ} \mathrm{C}$ and the strain level of $0.2 \%$ for $2000 \mathrm{~h}$. The microstructure and Brinell hardness of the samples before and after the relaxation test were studied by means of an optical microscope (OM), a field emission scanning electron microscope (FESEM) supplemented by energy dispersive spectrometry (EDS) and a Brinell hardness tester. For OM observation, the samples were mechanically polished and chemically etched in a solution containing $15 \mathrm{~g} \mathrm{CuCl} 2+100 \mathrm{ml} \mathrm{HCl}+100 \mathrm{ml} \mathrm{C} 2 \mathrm{H} 5 \mathrm{OH}$. For FESEM observation, the samples were electrolytic polished in a solution of $20 \% \mathrm{H} 2 \mathrm{SO} 4+80 \%$ $\mathrm{CH} 3 \mathrm{OH}$ with a voltage of $20 \mathrm{~V}$ and electrolytically etched in a solution containing $150 \mathrm{ml} \mathrm{H3PO} 4+$ $10 \mathrm{ml} \mathrm{H} 2 \mathrm{SO} 4+15 \mathrm{~g}$ CrO3 with a voltage of $5 \mathrm{~V}$. 
Creep rupture tests were also performed at $566^{\circ} \mathrm{C}$ and at different stress levels on the cylindrical specimens of $5 \mathrm{~mm}$ in diameter and $25 \mathrm{~mm}$ in gauge-length, which were machined from the aged alloy.

Table 1 Chemical composition of the investigated alloy / mass\%

\begin{tabular}{|c|c|c|c|c|c|c|c|c|c|c|c|}
\hline $\mathrm{C}$ & $\mathrm{Cr}$ & $\mathrm{Fe}$ & $\mathrm{Al}$ & $\mathrm{Ti}$ & $\mathrm{Nb}$ & $\mathrm{Si}$ & $\mathrm{Mn}$ & $\mathrm{S}$ & $\mathrm{P}$ & $\mathrm{Cu}$ & $\mathrm{Ni}$ \\
\hline 0.048 & 15.33 & 6.96 & 0.74 & 2.58 & 0.99 & 0.10 & 0.05 & 0.001 & 0.004 & $<0.07$ & Bal. \\
\hline
\end{tabular}

\section{Stress relaxation behavior}

Fig. 1 shows the relationship of remaining stress in the aged GH4145 alloy with relaxation time at $566{ }^{\circ} \mathrm{C}$. The curves can be divided into two stages. Stress drops very fast in the first stage while quite slowly in the second stage and residual stress approaches a limit after a long relaxation time. The initial stress was 364.7 MPa. After the test end at $2000 \mathrm{~h}$, the remaining stress was 327.3 MPa and stress decreased by only $10.3 \%$, implying that the alloy has good resistance to stress relaxation.

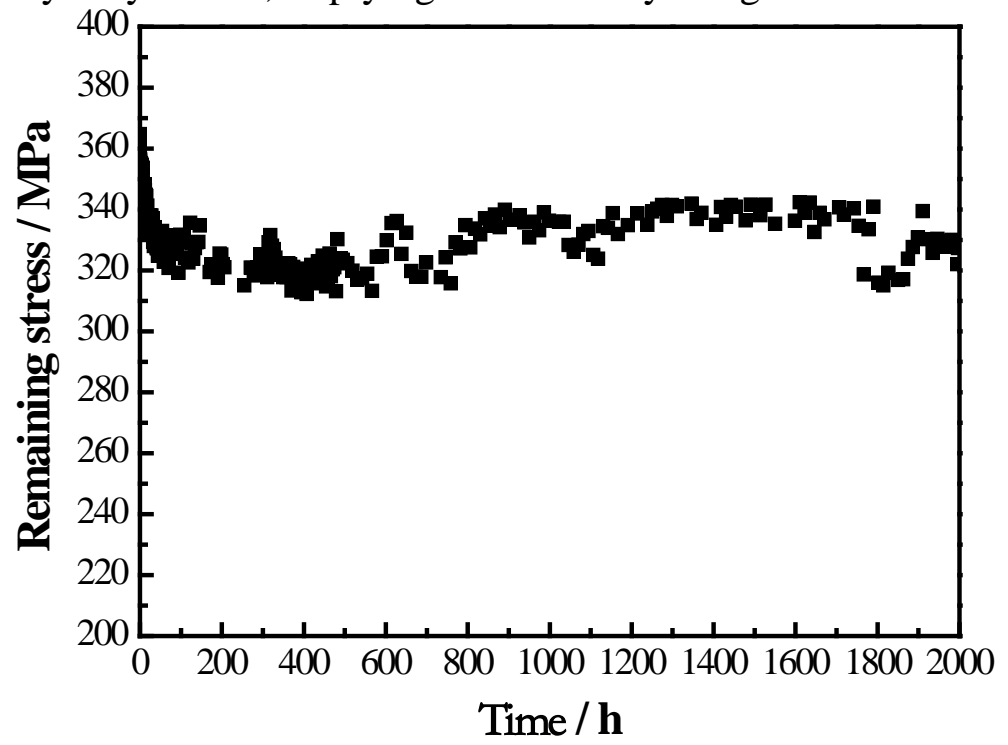

Fig. 1. Relationship of remaining stress in the aged alloy vs. relaxation time at $566^{\circ} \mathrm{C}$

Fig. 2 shows the microstructure of the alloy before and after the relaxation test. The optical microstructure of the aged alloy consisted of equiaxed grains of f.c.c. $\gamma$ with an average size of 117 $\mu \mathrm{m}$. Primary carbides of various sizes ranging from 1 to $10 \mu \mathrm{m}$ were aligned arrays, as shown in Fig. 2 (a). It is known that the precipitates in GH4145 alloy are mainly $\gamma^{\prime}$ phase and carbides [4]-[7]. Fig. 2 (b) shows the morphology and distribution of the precipitates in the aged alloy. It can be seen that $\gamma^{\prime}$ particles with different shapes and sizes, which are often referred to as secondary $\gamma^{\prime}$ precipitates, were distributed in grain interiors. The cuboidal $\gamma^{\prime}$ particles are surrounded by the spherical particles. The size of the former is significantly larger than that of the latter (see Table 2).

It is well known that the morphological development of $\gamma^{\prime}$ particles in nickel-base superalloys during coarsening proceeds in the sequence: spheres $\rightarrow$ cuboids $\rightarrow$ cuboidal arrays (a group of eight cuboids, i.e. an octet or a pair of parallel plates, i.e. a doublet) $\rightarrow$ dendrites [8]-[10]. The $\gamma^{\prime}$ particles are small and the interfacial energy dominates the coarsening process at the early stage of precipitation. As a result, the particles take a spherical shape. However, as $\gamma^{\prime}$ particles coarsen, the elastic strain energy associated with the misfit between the particle and the matrix structures dominates the coarsening process over the interfacial energy. Consequently, the morphology of $\gamma^{\prime}$ particles changes from spherical to cuboidal shape and an isolated cuboid splits into a doublet or an octet due to the anisotropic elastic strain field. In Fig. 2 (b), the cuboidal $\gamma^{\prime}$ particles were precipitated at the first-step aging treatment, whereas the spherical $\gamma^{\prime}$ particles were precipitated at the following second-step aging treatment [11]. Therefore, the size of the former is significantly larger than that of the latter and the morphology of the former was also changed from spherical to cuboidal shape. 


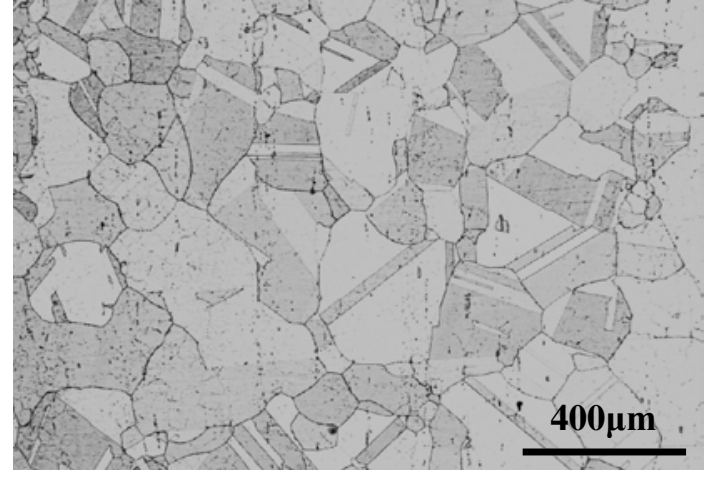

(a) Optical image, before the test

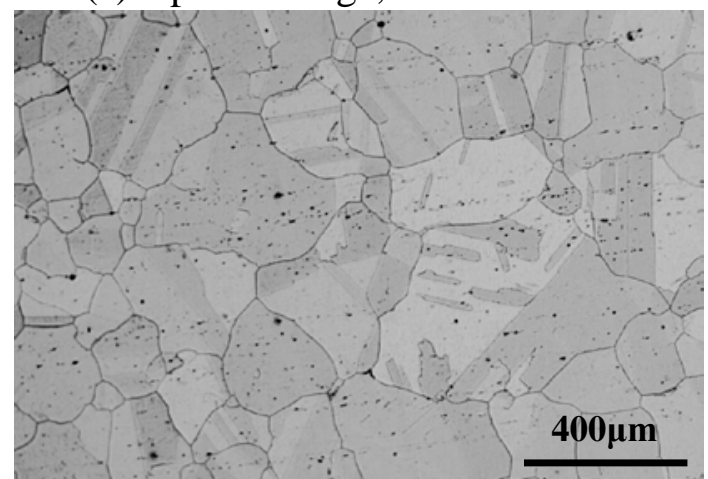

(c) Optical image, after the test

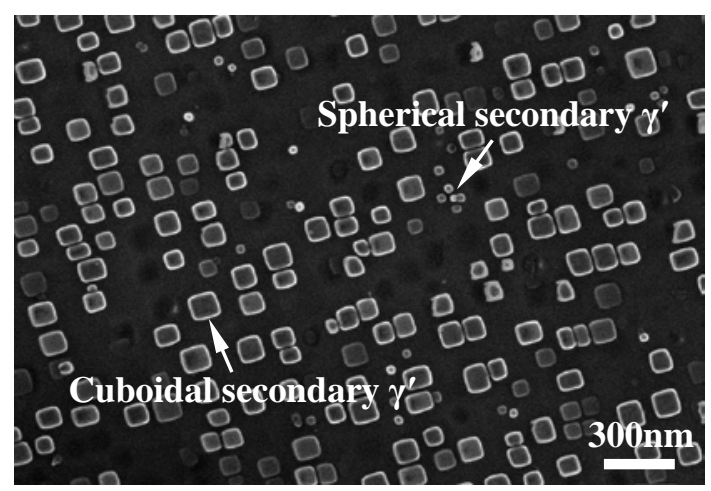

(b) SEM micrograph, before the test

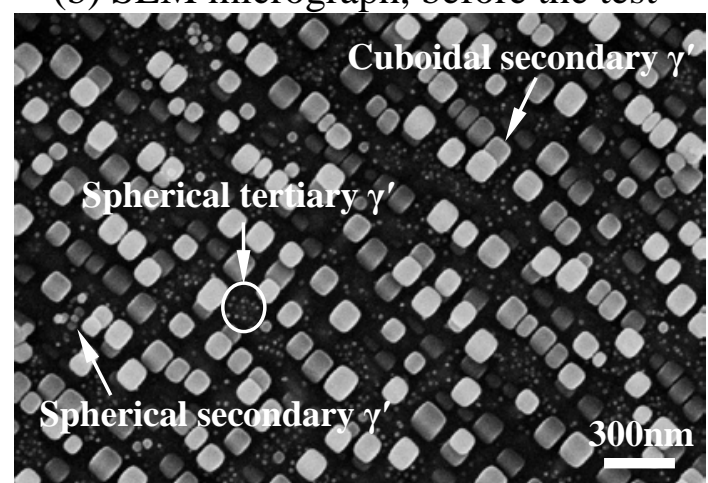

(d) SEM micrograph, after the test

Fig. 2. Microstructure of the alloy before and after the stress-relaxation test

Table 2 Average size of $\gamma^{\prime}$ precipitates in the alloy before and after the stress-relaxation test at $566^{\circ} \mathrm{C} / \mathrm{nm}$

\begin{tabular}{|c|c|c|}
\hline Precipitate & Before the test & After the test \\
\hline Cuboidal secondary $\gamma^{\prime}$ & 97.5 & 104.3 \\
\hline Spherical secondary $\gamma^{\prime}$ & 39.6 & 44.4 \\
\hline Spherical Tertiary $\gamma^{\prime}$ & - & 17.1 \\
\hline
\end{tabular}

After the relaxation test, the average grain size of the alloy increased from an initial value of 117 $\mu \mathrm{m}$ to about $160 \mu \mathrm{m}$. Although no obvious change can be found in the morphology and distribution of secondary $\gamma^{\prime}$ precipitates, but their average sizes increased slightly (see Table 2). In addition, spherical tertiary $\gamma^{\prime}$ particles with an average size of $17.1 \mathrm{~nm}$ were dispersedly precipitated in grain interiors.

The Brinell hardness values of the alloy before and after the relaxation test are given in Table 3 . It can be seen that the hardness of the alloy increased during the relaxation test.

Stress relaxation can be considered as special creep during which both stress and plastic strain rate decrease gradually, but the total strain remains constant. Creep resistance of nickel-base superalloys depends on such factors as solid solution hardening of the f.c.c. $\gamma$ matrix by the addition of alloying elements, e.g. Cr, Nb etc. (see Table 1), grain boundary strengthening by carbides and most importantly, on the ability of $\gamma^{\prime}$ phase to impede dislocation motion [12]. GH4145 alloy contains $\mathrm{Ti}$ and $\mathrm{Nb}$, which may partially substitute $\mathrm{Al}$ in the $\gamma^{\prime}$ phase and increase lattice mismatch between the $\gamma^{\prime}$ phase and matrix [4], making the strengthening effect of the $\gamma^{\prime}$ phase improve. It was reported that the $\gamma^{\prime}$ particles in GH4145 alloy may grow to the order of a few microns in diameter and still remain coherent with the matrix [5]. Therefore, the alloy has good resistance to stress relaxation. Moreover, the precipitation of fine tertiary $\gamma^{\prime}$ particles in grain interiors during the relaxation test made the strength and hardness of the alloy increase and the creep rate decrease further. 
Table 3 Brinell hardness of the alloy before and after the stress-relaxation test at $566{ }^{\circ} \mathrm{C}$

\begin{tabular}{|c|c|c|}
\hline Hardness & Before the test & After the test \\
\hline HBW 5/750 & 300 & 346 \\
\hline
\end{tabular}

\section{Stress rupture property}

Fig. 3 shows the creep rupture life of the aged GH4145 alloy under different stress levels at $566{ }^{\circ} \mathrm{C}$. The rupture time increased from 186.5 to $2817.3 \mathrm{~h}$ when the applied stress dropped from 780 to $680 \mathrm{MPa}$. The relational expression between stress and rupture time can be obtained by a linear regression analysis of experimental data in Fig. 3 and is shown as follows:

$\lg \sigma=3.004-0.0495 \lg \mathrm{t}$

where $\sigma$ is the applied stress, $t$ is the rupture time (i.e. the creep rupture life). The correlation coefficient of the above fitting is 0.9991 . The creep rupture strength for times longer than that of the experimental data can be estimated by using the above equation.

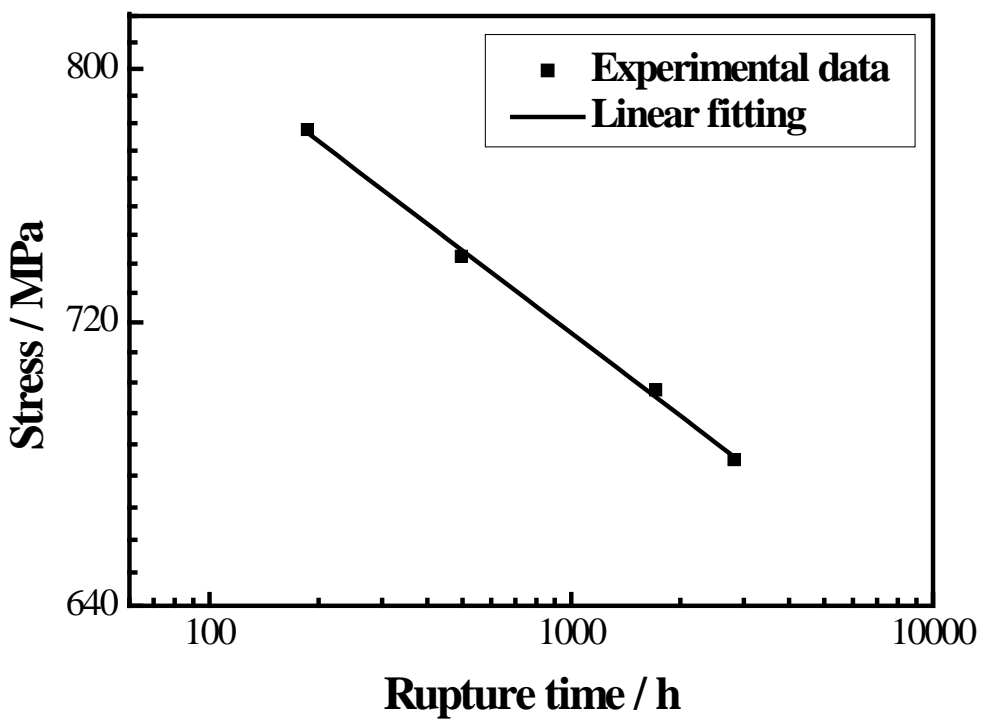

Fig. 3. Stress vs. creep rupture time curves for the aged alloy at $566^{\circ} \mathrm{C}$

\section{Conclusions}

GH4145 alloy has good resistance to stress relaxation. During the stress relaxation test at $566{ }^{\circ} \mathrm{C}$, although the average grain size of the alloy obviously increased, the coarsening rate of secondary $\gamma^{\prime}$ phase is very slow. The precipitation of tertiary $\gamma^{\prime}$ particles made the hardness of the alloy increase.

The relational expression between stress and creep rupture life for GH4145 alloy at $566{ }^{\circ} \mathrm{C}$ was obtained. The creep rupture strength for times longer than that of the experimental data can be estimated by using this equation.

\section{References}

[1] H. Rubel, D. Marschke, J. Tautz, G. Micheel. Inconel X-750 as material for core internals and core components - status of in-service experience and replacements at Siemens KWU Group [J]. Nucl. Eng. Des., 1989112 (3) 329-336.

[2] D. Ye, Z. Wang, X. Yin. An investigation of the effect of high-temperature cyclic straining and creep loading on tensile mechanical properties of GH4145/SQ alloy [J]. J. Mater. Sci., 200540 (24) 6483-6494.

[3] G. Lothongkum, W. Khuanlieng, W. Homkrajai, P. Wangyao. Effect of aging on stress relaxation of Inconel X-750 bolt at 923 and 1023 K [J]. High Temp. Mater. Processes, 200625 (4) 
175-185.

[4] J. A. Del Valle, A. C. Picasso, I. Alvarez, R. Romero. Age-hardening behavior of Inconel X-750 superalloy [J]. Scripta Mater., 199941 (3) 237-243.

[5] A. K. Sinha, J. J. Moore. Study of precipitation and growth of $\gamma^{\prime}$ and dislocation structure in Inconel X-750 [J]. Metallography, 198619 (1) 75-86.

[6] A. K. Sinha. Growth of MC particles on stacking faults and dislocations [J]. Metallography, 198720 (1) 37-45.

[7] A. K. Sinha, J. J. Moore. Precipitation of M23C6 carbides in an aged Inconel X-750 [J]. Metallography, 198619 (1) 87-98.

[8] R. A. Ricks, A. J. Porter, R. C. Ecob. The growth of $\gamma^{\prime}$ precipitates in nickel-base superalloys [J]. Acta Metall., 198331 (1) 43-53.

[9] Y. Y. Qiu. Retarded coarsening phenomenon of $\gamma^{\prime}$ particles in Ni-based alloy [J]. Acta Mater., 199644 (12) 4969-4980.

[10] P. R. Cha, D. H. Yeon, S. H. Chung. Phase-field study for the splitting mechanism of coherent misfitting precipitates in anisotropic elastic media [J]. Scripta Mater., 200552 (12) 1241-1245.

[11] E. Nembach, J. Pesicka, V. Mohles, D. Baither, V. Vovk, T. Krol. The effects of a second aging treatment on the yield strength of $\gamma^{\prime}$-hardened NIMONIC PE16-polycrystals having $\gamma^{\prime}$-precipitate free zones [J]. Acta Mater., 200553 (8) 2485-2494.

[12] R. A. Stevens, P. E. J. Flewitt. The dependence of creep rate on microstructure in a $\gamma^{\prime}$ strengthened superalloy [J]. Acta Metall., 198129 (6) 867-882. 